\title{
Experiential Marketing and Customer Satisfaction: A Study on the Restaurant Industry of Bangladesh
}

\author{
Sanjida Amin ${ }^{1 *}$, Md Touhiduzzaman Tarun² \\ ${ }^{1}$ Lecturer, Department of Marketing, Faculty of Business Studies, Bangladesh University of Professionals (BUP), Dhaka, BANGLADESH \\ 2Executive, Training. MetLife, Dhaka, BANGLADESH \\ *E-mail for correspondence: sanjida.2016prema@gmail.com
}

https://doi.org/10.18034/abr.v9i1.251

\begin{abstract}
This research report aims to explore the factors of experiential marketing to determine their impact on customer satisfaction in the restaurant industry of Bangladesh. Three Hypotheses were developed by the researcher to identify the factors of experiential marketing and their impact on overall customer satisfaction. The research study is conducted by a quantitative research approach to get the insights and understandings of experiential marketing and to figure out the strength of association between dependent and independent variables. Empirical data was gathered by the author himself from 150 respondents who were present in the restaurants at that time through the self-administered survey questionnaire. By applying a convenience sampling method, the researcher collected data from the respondents under different clusters. Researcher used regression and factor analysis to analyze the statistical data through the SPSS software. The research concluded with the significant positive relationships of sense experience, feel experience, and think experience with customer satisfaction. The outcome of the study will assist managers, restaurant owners and, decision makers with the insights and understanding of experiential marketing and its influence on customer satisfaction.
\end{abstract}

Key words: Experiential marketing, Customer satisfaction, Restaurant industry, Bangladesh

\section{INTRODUCTION}

The rapid growth of marketing that focuses on service excellence and experience rather than product's features and attributes has challenged the marketers to engage experiential marketing approach in designing the marketing strategies by involving customers (Phil Klaus \& Maklan, 2012). Experiential marketing is one of the noteworthy approaches that give a great framework to combine experience, memories and entertainment elements into a product or service. Although consumer experience is recognized as one of the benefits provided by hospitality and tourism industry, the use and application of experiential marketing in this industry is not well demonstrated. The current study's findings have indicated that customers in different restaurants prefer memorable, creative and memorable experiences. This fact stresses the importance of the experiences which manage to evoke the customer's inner feelings and challenge their mind. Therefore, there is a vast field of possibilities for restaurateurs to use their imagination and creativity to engage with the clients in different ways by using these experiential marketing practices.
The Significance of the study: Even though experiential marketing is an emerging marketing field and restaurant business until now has focused mainly on the traditional marketing approaches, the current study's findings have indicated that customers in different hotel and restaurants prefer vivid, creative and memorable experiences. This fact shows the significance of the experiences which managers may apply to evoke the customer's significant inner feelings and change their mind. Therefore, there is huge scope for restaurateurs to use their thoughts, innovation and creativity to serve customers in different ways by applying these diversified experiential marketing practices. This research project will help the restaurant managers and decision makers identifying the factors or attributes of experiential marketing and the significance of them determining the level of customer satisfaction of the restaurant business in Bangladesh. The report will also help the managers to figure out the impact of experiential marketing on customer satisfaction especially in the hospitality and tourism sector. The solutions based on the recommendations presented in the later part of the report 
will help them to solve any existing problems and to utilize the opportunities regarding factors of experiential marketing and its implications in the hospitality and tourism industry.

\section{Objectives of the Study}

This study attempts to achieve the following objectives:

- To examine whether feel perception influences customer satisfaction

- To examine whether sense perception has an impact on customer satisfaction

- To examine whether think perception influences customer satisfaction

\section{LITERATURE REVIEW}

Experiential marketing is a shift from one-to-all communication, where the marketers try to attract customers' attention through one-way communication, which is known as individual or one-to-one marketing, because customers require personal attention, they need interaction with the company and are ready to respond by participating in active communication. Service industry like tourism industry and restaurant business have an extra advantage in the experiential marketing context, as the nature of business enables marketers to have a dialogue with customers and provides personal experiences directly. To satisfy the customer, it is necessary to create the first memorable, pleasurable, caring, sensual and sometimes extraordinary experiences. So the challenge for business marketers and researchers is to identify what experiences can leave the most favorable impression on customers and encourage them to develop a positive attitude and behavior towards the brand.

The term experiential marketing refers to the customers' development of the recognition and visualization and purchasing a subsequent number of goods or services from any organization after they experience the services, activities and perceive stimulations (Schmitt 1999). Several studies found that there are several crucial factors of experiential marketing including experience, Environments, atmospheres, layouts which are generally created by businesses with a view to providing experience to the customers (Yuan \& Wu, 2008). Thus it has been concluded that Creating and providing sustainable, memorable and unique experiences to the customers is gaining more importance and priority in business especially in the service sector to gain a competitive advantage over others (Rageh Ismail et al., 2011). Whereas traditional marketers consider that people make a choice based on the functional attributes, experiential marketers view consumers as rational and emotional human beings who are concerned about achieving pleasurable and exciting memorable experiences (Schmitt, 1999). Sense experience includes customers experience gaining from using customers' all the sensors like sight, touch, taste, etc. McCole (2004). Schmitt, (1999) concluded that sense marketing could be used in the field of marketing while differentiating products from the competitors and while persuading customers

Another important dimension of experiential marketing is to feel experiences which can be gained using customers' inner feelings, motives, emotions, expressions and mood (Yuan \& Wu, 2008).

In 1999, Schmitt discovered that with the positive feelings that are generated in the consumption process, consumer develops a positive emotion (Schmitt, 1999).

The researchers studied that think experience emphasizes on the intelligence of the consumer in generating cognitive experience (Lee et al., 2010). According to Schmitt (1999), think experience stimulates and reinforces customers' creative thinking while they develop a new thought or innovate something about a company or its products or services. Thus Through the processing of creating a new idea or thinking, consumers forms their own evaluation towards the company and its brand. Schmitt (1999) concluded that Think marketing is a major component of experiential marketing that raise the question of the intellect of the customers by creating exotic experiences for the customers to be engaged in several creative activities through surprise, stimulations, intrigue and provocation.

Today, customers are so dynamic and sensitive that they no longer compromise the quality of the food, service provided by the owner and dining environment just for the good taste of the food (Ryu et al., 2012). Lee et al., (2010) mentioned customer satisfaction as the psychological engagement of the customer who evaluates the difference between perceived and actual consumption process of specific products and services. Lee et al. (2010) in their study on discount shopping malls proved that experiential marketing has a significantly positive influence on the customer's satisfaction. Equivalent researches were made in hospitality business environment - the research involving cruise tourists indicated that tourists' experiences have a significant positive effect on their satisfaction (Hosany and Martin, 2012).

Similarly, Jin et al. (2013) in their study on full-service restaurants in the U.S. revealed that entertaining environment, pleasant service and additional value (money, time, etc.) encourage the customer's trust and satisfaction. Furthermore, Pantelidis (2010) in his research, based on the content analysis of customer comments on an online restaurant guide, proved that the top three factors explaining customer satisfaction in restaurant business are food quality, service, and atmosphere. 


\section{Methodology OF THE STUDY}

\section{Sample and data collection}

The study is descriptive in where the objective is to describe the market characteristics or function, and it is characterized by the prior formulation of hypotheses that have been drawn in the previous section. Quantitative analysis was used by the researcher to find the strength of association of the independent variables with the dependent variable. A Self-administrative questionnaire was used in the study to collect primary data from the customers of the restaurant industry of Bangladesh. Due to the resource constraints, the required data for the study have collected from a representative pool of the target population. To make the sample representative one, the researcher developed few clusters of the restaurants based on the regions named Dhanmondi, Gulshan, Banani, Mirpur, Motijheel, Uttara and old Dhaka. By applying convenience sampling, the researcher collected data from the respondents under different clusters. As a process of data collection, the researcher distributed 150 questionnaires to the restaurant managers to collect data from the respondents. In this study, the customers were asked to respond through the items using a 5-point Likerttype scale ( 1 = 'strongly disagree'; $5=$ 'strongly agree'). The current study employed SPSS as a statistical tool to analyze the data.

\section{Research Hypotheses}

Three Alternative hypotheses, often referred to as the unproven proposition, of the study were formulated regarding the impact of experiential marketing on customer satisfaction. The hypotheses are as follows:

H1: Feel Perception has a positive impact on Customer Satisfaction

$\mathbf{H}_{2}$ : Sense Perception has a positive impact on Customer Satisfaction.

$\mathbf{H}_{3}$ : Think Perception has a positive impact on Customer Satisfaction

\section{ANALYSIS AND DISCUSSIONS}

\section{Reliability and Validity}

The variables that have been used for collecting primary data are metric and five points Likert scale has been used in the study for measuring the variables to identify their impact on customer satisfaction.

Table 1: Reliability and the Validity of the Variables

\begin{tabular}{|c|c|}
\hline \multicolumn{2}{|c|}{ Reliability Statistics } \\
\hline Cronbach's Alpha & N of Items \\
\hline .870 & 19 \\
\hline
\end{tabular}

The reliability and the validity of the variables have been tested by using Cronbach's Alpha where the value is .870 which is larger than .60 and ensured the reliability and validity of the instruments. The construct validity of the scale can be established from factor analysis discussed below.

\section{Factor Analysis}

In the current study, a principal component factor analysis has been conducted by the researcher so that the researcher can identify and sort out the factors related to the respondents' satisfaction and experiential marketing. The value of chi-square statistics is 1713.621 with 171 degrees of freedom, at $5 \%$ level of significance which indicates that Bartlett's test of sphericity shows the high correlation among the variables. The value of $\mathrm{KMO}$ statistics (0.904) which is larger 0.5 shows the appropriateness of factor analysis.

Table 2: KMO and Bartlett's Test

\begin{tabular}{|l|l|l|}
\hline $\begin{array}{l}\text { Kaiser-Meyer-Olkin Measure } \\
\text { of Sampling Adequacy }\end{array}$ & .904 \\
\hline \multirow{2}{*}{$\begin{array}{l}\text { Bartlett's Test } \\
\text { of Sphericity }\end{array}$} & Approx. Chi-Square & 1713.621 \\
\cline { 2 - 3 } & $\mathrm{df}$ & 171 \\
\cline { 2 - 3 } & Sig. & .000 \\
\hline
\end{tabular}

The researcher here conducted a principal component factor analysis, which considers the total variance in the data and determines the minimum number of factors that will account for maximum number of the variance in the data for use in the subsequent multivariate analysis. Several procedures have been suggested for determining the number of factors; however the author has determined the factors based on the Eigenvalues. Principal component factor analysis on the 19 variables yielded a 3factor solution having Eigenvalues more than $1(€>1)$, that explained $61.43 \%$ of the total variance as represented in Table 3. Attributes with a factor loading below 0.5 are not considered. According to the variables that are represented under one factor, the names of the three major factors have been identified as Sense, Feel and, Think perception. Thus, focusing on these factors would enable the concerning authorities to achieve the desired goal that is measuring the impact of experiential marketing factors on customer satisfaction.

Table 3: Factors influencing experiential marketing

\begin{tabular}{|c|c|c|c|}
\hline Component & $\begin{array}{c}\text { Initial } \\
\text { Eigen value }\end{array}$ & \% of Variance & Cumulative \% \\
\hline 1 & 8.978 & 23.775 & 23.775 \\
\hline 2 & 1.413 & 18.967 & 42.741 \\
\hline 3 & 1.281 & 18.689 & 61.430 \\
\hline
\end{tabular}

The first factor, Feel-perception accounts for the most variance which is $23.78 \%$. The nine variables contained in this factor are Reliability, Fun with Friends, Inner Environment, Security, Memorable experience, Modern equipment, Systematic service, Responsiveness and Feel of membership. The factor loading points for these 
variables are considerably higher than .50 . Hence, these variables explain a significant amount of customers' satisfaction toward experiential marketing. The second most important factor is Think-perception which explains $18.97 \%$ of the variation in customers' satisfaction toward the tools of experiential marketing. This factor includes Dress code, Staff's behavior, new experience, Price of food and Quality of food. The factor loading points for these variables are also higher than .70. Thus, the factor named think perception also playing a significant role in defining customer satisfaction.

The third most important factor is Sense-perception. Variables included in this component are Light, Color, Interior decoration, Atmosphere and Care of the staff's. The factor loading points are also substantially higher, which shows the factor's significance in determining satisfaction toward the importance of experiential marketing. From the above discussion, it can be discerned that three identified factors are represented by nineteen variables.

\section{Selecting the surrogate variable}

To carry out regression analysis, the author made use of the surrogate variable rather than factors score. To identify the surrogate variable, the author has considered the variables which have the highest loading in each of the factors and, this allowed including three independent variables named quality of food, Fun with friends and light brightness, in the regression analysis.

Table 4: Principal component factor analysis: Impact of experiential marketing on customer satisfaction

\begin{tabular}{|c|c|c|c|c|}
\hline $\begin{array}{l}\text { Factor } \\
\text { name }\end{array}$ & Variables & $\begin{array}{c}\text { Factor } \\
\text { loading }\end{array}$ & \begin{tabular}{|c|}
$\%$ of \\
variance \\
explained
\end{tabular} & \begin{tabular}{|c|} 
Cronbach's \\
reliability \\
coefficient $(\alpha)$ \\
\end{tabular} \\
\hline \multirow{9}{*}{$\begin{array}{c}\text { F1(Feel } \\
\text { Perception) }\end{array}$} & Reliability & .610 & \multirow{9}{*}{23.78} & \multirow{9}{*}{.7351} \\
\hline & Fun with friends & .826 & & \\
\hline & Inner environment & .650 & & \\
\hline & Security & .755 & & \\
\hline & $\begin{array}{l}\text { Memorable } \\
\text { experience }\end{array}$ & .607 & & \\
\hline & Modern Equipment & .554 & & \\
\hline & Systematic service & .695 & & \\
\hline & Responsiveness & .576 & & \\
\hline & Feel of membership & .477 & & \\
\hline \multirow{5}{*}{$\begin{array}{c}\text { F2 } \\
\text { (Think } \\
\text { perception) }\end{array}$} & Dress code & .584 & \multirow{5}{*}{18.97} & \multirow{5}{*}{.7153} \\
\hline & Staff's Behaviour & .634 & & \\
\hline & New experience & .726 & & \\
\hline & Price of food & .698 & & \\
\hline & Quality of food & .553 & & \\
\hline \multirow{5}{*}{$\begin{array}{c}\text { F3 } \\
\text { (Sense } \\
\text { perception) }\end{array}$} & Light & .818 & \multirow{5}{*}{18.69} & \multirow{5}{*}{.8138} \\
\hline & Colour & .730 & & \\
\hline & Interior decoration & .761 & & \\
\hline & Atmosphere & .640 & & \\
\hline & Care of the staff's & .576 & & \\
\hline
\end{tabular}

The first factor Feel perception has seven variables. Among them, "Fun with friends" has the highest factor loadings. Hence, this variable is selected as the surrogate variable for the first factor. 'New experience' has the highest loading (.726) with the second factor but 'quality of the product (food),' making it the surrogate variable because this variable has been more justified in similar studies rather than the previous one. The third factor contains five variables and 'light brightness' variable loads highest (.818) among them. Thus, a total of three variables have been selected to carry out a subsequent regression analysis.

\section{Regression Analysis}

A multiple regression technique was then employed. The researcher considered Customers' overall satisfaction as the dependent variable and three surrogate variables as independent variables, respectively.

Table 5: Results of Regression

\begin{tabular}{|c|c|c|c|}
\hline Variables & Beta's & Computed t & Significance \\
\hline $\begin{array}{c}\text { The light brightness } \\
\text { of restaurant }\end{array}$ & .229 & 3.607 & .000 \\
\hline Fun with friends & .304 & 4.836 & .000 \\
\hline Quality food & .419 & 6.692 & .000 \\
\hline
\end{tabular}

The results of the regression analyses revealed that out of three control variables, almost three- the light brightness of restaurant, fun with friends and quality food had statistically significant effects and positively related on the customer satisfaction. This statistical outcome indicates that these variables deserve more attention in the attempt to improve the current satisfaction level of the customers towards the ambiance of the restaurants. Next, in table 6, $R$ is the value of multiple correlation coefficient between the predictors and the outcome. The outcome of the analysis shows the simple correlation between the factors of experiential marketing and overall customer satisfaction. Then the value of $R^{2}$ measures how much of the variability in the dependent variable is accounted for by the predictors. The result of the $R^{2}$ value in table 6 indicates that almost $51 \%$ of the variation in the dependent variable can be explained by the independent variables.

From the above analysis it can be concluded that constructs of experiential marketing and perception of experiential marketing can significantly influence customers' satisfaction. The outcome of the study is also found consistent with the previous researchers (Lin, Chang, Lin, Tseng, \& Lan, 2009). Furthermore, the result of the current study also implies that positive perception of experiential marketing may induce customer satisfaction which in turn may influence customers' loyalty and actual behavior (Bagozzi, 1992).

\section{IMPLICATIONS OF THE FINDINGS}

On this ground these, several recommendations have been constructed here for managerial implications:

- The current study concluded that the factors of experiential marketing can influence customer 
satisfaction level and they have synergetic effects on each other simultaneously. Therefore, it can be said that the empirical outcome of this study may serve as the guideline for the future research regarding various dimensions of experiential marketing and customer satisfaction.

- This article will help the managers to identify the factors and attributes of experiential marketing affecting the restaurant business of Bangladesh and also to discover the interrelationships among them.

- From the findings of the study it can be suggested that restaurant managers should take experiential marketing as an innovative idea to provide outstanding offers to the customers. However, they should not think that their customers are rational and they decide based on functional product features and attributes, for example, price and quality. Therefore, the article may help to understand managers that they should take account of "excellent, memorable and unique experiences" for customers.

- Finally, the outcomes of this article will provide several insights regarding appropriate strategies and will also give empirical supports for managers to implement experiential marketing strategies to influence the level of customer satisfaction.

\section{CONCLUSION}

Generally, the results of this study conclude that experiential marketing can induce customer satisfaction because all three hypotheses have been supported here. The results of this report show that each experience of experiential marketing has a significant effect on the emotion of the customer and then, in turn, influences the consequent visitor's evaluation, behaviors and revisit intention. On these grounds, thus a favorable, meaningful and memorable experiential environment leads its customers to develop a higher satisfaction level. It is also suggested by the author that to establish and to maintain a desirable experiential environment; it is a mandatory and crucial issue to achieve a competitive advantage that is difficult to be imitated by any of the competitors. To develop a higher visitor's satisfaction and favorable behavioral impressions, restaurant marketers have to review its experiential environment by measuring each strategic experiential module frequently and tactically.

\section{REFERENCES}

Bagozzi, R. (1992). The Self-Regulation of Attitudes, Intentions, and Behavior. Social Psychology Quarterly, 55(2), 178. doi: $10.2307 / 2786945$

Hosany, S. and Martin, D., 2012. Self-image congruence in consumer behavior. Journal of Business Research, 65(5), pp.685-691.

Jin, N., Line, N.D. and Goh, B., 2013. Experiential value, relationship quality, and customer loyalty in full-service restaurants: The moderating role of gender. Journal of Hospitality Marketing \& Management, 22(7), pp.679-700.

Lee, M.S., Hsiao, H.D. and Yang, M.F., 2010. The study of the relationships among experiential marketing, service quality, customer satisfaction and customer loyalty. International Journal of Organizational Innovation, 3(2).

Lin, K. M., Chang, C. M., Lin, Z. P., Tseng, M. L., \& Lan, L. W. (2009). Application of experiential marketing strategy to identify factors affecting guests' leisure behaviour in Taiwan hot-spring hotel. WSEAS transactions on business and economics, 6(5), 229-240.

McCole, P., 2004. Refocusing marketing to reflect practice: The changing role of marketing for business. Marketing Intelligence $\mathcal{E}$ Planning, 22(5), pp.531-539.

Pantelidis, I.S., 2010. Electronic meal experience: A content analysis of online restaurant comments. Cornell Hospitality Quarterly, 51(4), pp.483-491.

Phil Klaus, P. and Maklan, S., 2012. EXQ: a multiple-item scale for assessing service experience. Journal of Service Management, 23(1), pp.5-33.

Rageh Ismail, A., Melewar, T.C., Lim, L. and Woodside, A., 2011. Customer experiences with brands: Literature review and research directions. The Marketing Review, 11(3), pp.205-225.

Ryu, K., Lee, H.R. and Gon Kim, W., 2012. The influence of the quality of the physical environment, food, and service on restaurant image, customer perceived value, customer satisfaction, and behavioral intentions. International Journal of Contemporary Hospitality Management, 24(2), pp.200-223.

Schmitt, B., 1999. Experiential marketing. Journal of marketing management, 15(1-3), pp.53-67.

Yuan, Y.H.E. and Wu, C.K., 2008. Relationships among experiential marketing, experiential value, and customer satisfaction. Journal of Hospitality $\mathcal{E}$ Tourism Research, 32(3), pp.387-410.

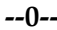


Online Archive: https://abc.us.org/ojs/index.php/abr/issue/archive 